\title{
O JUDEU-HELENISMO E AS ORIGENS DO CRISTIANISMO
}

\author{
Laura Graziela F. F. Gomes \\ Universidade Federal Fluminense
}

Resumo: Este trabalho tem como objetivo apresentar algumas considerą̧⿸丆巳es gerais sobre o contexto inaugural do Cristianismo com vistas a relativizar as abordagens sociológicas que interpretam a ocorrência do Messianismo nas sociedades modernas $e$ contemporâneas como algo "deslocado", sintoma de arcaísmo e de irracionalidade. Pretenderemos demonstrar que tais abordagens geralmente ignoram o fato de que, desde o início, este sistema religioso está fundado numa tensão - esta podendo ser reduzida à oposição Fé X Razão - em virtude do lugar e do papel desempenhado pela civilização helenística e pelo Judaísmo em sua constituição.

Palavras-chave: Cristianismo Primitivo, Judaísmo, Messianismo, Sincretismo e Civilização Helenística.

Para falarmos das origens do Cristianismo é preciso, antes de tudo, entendermos dois problemas fundamentais: o lugar da civilização helenistica e 0 papel desempenhado pelo Judaísmo na formação de uma economia simbólica, levando-se em conta o pano de fundo de uma valorização crescente do indivíduo como centro da vida social. Nosso enfoque, entretanto, não se destina à reconstrução do período histórico em questão. Ele se inspira nas idéias de Max Weber ${ }^{1}$ e nas pesquisas desenvolvidas pela Escola Sociológica Francesa, para a qual a Antropologia "não procura estudar as formas antigas de civilização apenas no intuito de conhecê-las ou reconstitur-las ... ela tem como objetivo explicar uma realidade atual, próxima de nós" (Durkheim, 1960, p.29). 0 que nos motivou a este trabalho é a possibilidade de podermos relativizar uma interpretação sociológica que situa a ocorrência de uma visão de mundo messiânica ${ }^{2}$ em sociedades modernas e contemporâneas como um sintoma de arcaísmo e incapacidade de elas sustentarem de fato a sua pretensão à modernidade. Uma modernidade que segundo Max Weber, é definida como um processo de individualismo crescente, de inevitável laicização da vida social e desencantamento do Mundo. Nossas intenções, à medida que retornamos às origens do Cristianismo, é relativizar esta postura, algo que no nosso entender aponta para uma percepção evolucionista, etnocêntrica e hierarquizadora, tanto da história do Cristianismo como das sociedades que compõem a chamada civilização ocidental moderna.

1. WEBER, Max. A Ética Protestante e o Espirito do Capitalismo. São Paulo: Ed. Pioneira, 1967.

2. Bem entendido, aqui trataremos exclusivamente do Messianismo ou dos Messianismos que se desenvolvem tendo como quadro de referência o Cristianismo nas suas diferentes expressões. Portanto, não estamos falando de visões de mundo também denominadas de messiânicas pelos antropólogos, existentes em algumas sociedades tribais, como e o caso dos Guaranis 
Antes de iniciarmos propriamente o nosso trabalho, devemos lembrar que nossa incursão pelo período helenistico não será feita, pelo menos por agora, a partir da utilizaçăo e da consulta à totalidade do corpus térico e literário existente, como o faria um especialista. Nossa abordagem privilegiará algumas interpretações já feitas por alguns desses especialistas que, neste caso, serão tomados como nossos informantes qualificados ${ }^{3}$.

Por isso mesmo, iniciaremos o trabalho citando Louis Dumont ${ }^{4}$, cuja obra muito nos tem orientado. Segundo ele, Alexandre Koyré já tinha feito uma observação interessante: 0 que existe de comum entre "a loucura do Cristo" e "o bom senso do Buda" é "a preocupação exclusiva do individuo unida a - ou melhor, fundada em - uma desvalorização do mundo" (Dumont, 1983, p.43). É bem verdade - e este é 0 objeto de toda a discussão proposta por Dumont - que esta "desvalorização do mundo" deve ser bastante relativizada no caso do Cristianismo. Em resumo, 0 que 0 autor se pergunta é o seguinte: quais são as possibilidades de emergência do individuo e do individualismo numa sociedade de castas (no caso da India), hierárquica e holista (no caso indo-europeu em geral) e numa comunidade - a judaica - que, desde as suas origens, em função de sua especificidade histórica, caracterizou-se por um igualitarismo sem precedentes e sempre transitou entre "um particularismo suspicaz e um universalismo receptivo" (Simon \& Benoit, 1987, p.50)?

No caso do budismo ${ }^{5}$, que foi responsável por notáveis inovações religiosas e sociais na India, Buda é o renunciante por excelência, e a sua renúncia assenta-se numa experiência distinta da renúncia cristã: a certeza de que a busca da verdade última deve ter como premissa a relativização da vida no mundo, seguida do abandono das restrições que ela implica "para consagrar-se ao seu progresso e destino próprios" (Dumont, 1983, p.38). Mas, de acordo com Louis Dumont, essa busca não exige uma reação contra o mundo. Ao contrário, este renunciante depende do mundo tal como ele é. Seu objetivo apenas o coloca distanciado da existência mundana, qualquer que seja ela. Este mundo, por outro lado, reserva um lugar para ele tanto em termos de garantir a sua subsistência, quanto de estabelecer sua função social nele. Diante disso, muitos estudiosos do budismo já o definiram mais como um sistema filosófico do que uma religiăo, tal é o valor que o budismo confere ao processo de busca e de aperfeiçoamento tomados em si mesmos, isto é, sem estarem vinculados à existência de um mundo sobrenatural ou a uma teleologia. Neste caso, o Nirvana é concebido como um estado e uma condição do ser.

Ora, para efeitos práticos, este renunciante para o qual o Buda, o budismo e a India parecem constituir um paradigma - de um contexto, de um tipo social, de

3. Devemos esclarecer que esta questăo sobre a utilização das fontes e do discurso histórico pela Antropologia, assim como a utilização pela História das toorias e dos métodos de pesquisa antropológica tem se constituido numa área de grande interesse e discussão no interior destes dois campos de conhecimento. De resto, procederemos de acordo com a tradiçăo da Escola Sociológica Francesa cujos principais autores partiram de uma releitura de trabalhos ja existentes.

4. DUMONT, Louis. Essais sur L'Individualisme: une perspective anthropologique sur l'idéologie modeme. Paris: Éditions du Seuil, 1983.

5 Tudo indica que o nascimento do budismo ocorreu em torno do século V A.C. Portanto, Buda seria contemporâneo de Sócrates. 
um modo de ação bastante definido -, ao que tudo indica, não era desconhecido no mundo greco-romano e greco-oriental ${ }^{6}$. A partir do século IV A.C., fosse isto em razão das conquistas de Alexandre e de sua política de aproximação com os persas e com os povos do extremo oriente, fosse porque, afinal, gregos, persas e mais adiante os romanos, não "podiam ignorar as idéias que a sociedade de casta alimenta" (Dumont, 1983, p.74), este renunciante - 0 ancestral do individuo no contexto indo-europeu - difundiu-se pelo mundo helenístico. De acordo com Dumont, o que temos é um individualismo legitimado na forma da renúncia e da ascese que no periodo helenístico já se constituira em um modo de vida difundido entre grupos sociais ilustrados, para os quais ela tinha se tornado um modelo ético de conduta. Desse modo, segundo Dumont e outros historiadores, dificilmente 0 Cristianismo poderia prosperar num ambiente que desconhecesse completamente $e$ não valorizasse de alguma maneira estas formas de renúncia.

Mas o que explica tal transformação em relação aos períodos anteriores? Tudo indica que a experimentação intensa e sistemática da diversidade cultural no período helenístico acarretou o esgotamento do modelo do homem político, autosuficiente, ancorado na Polis - modelo em que 0 individuo ainda nã̃o se encontrava dissociado do cidadão. Em função deste novo ambiente político e cultural, tal dissociação ocorre não apenas em termos conceituais (filosóficos) mas principalmente em termos de uma experiência generalizada. É a chamada "época da ansiedade" a qual se refere Dodds e tantos outros historiadores. A conseqüência disso foi a procura cada vez mais intensa de formas de "redução desta ansiedade", seja pela via da religião - digga-se religiões de mistério -, seja pela via de uma espécie de "terapia ética" através do "distanciamento inteligente" promovido pela vinculação a uma escola filos6fica. Mas é preciso ressaltar que, mesmo se levando em conta as diferentes escolas filosóficas existentes, 0 objetivo não era 0 de romper com 0 mundo em redor. Se por um lado se vivia uma época de ansiedade, o clima até os séculos III d.C. era de tolerância geral, conforme escreveu Arnaldo Momigliano. Temos também que admitir com este autor que, caso o individualismo filosófico não tivesse encontrado resistência no mundo helenístico, mais exatamente entre um de seus grupos minoritários, os judeus, poderia ter prevalecido na nova civilização que começava a se estruturar "um vago gnosticismo alexandrino ... em vez da disciplina cristã imposta pelas duas Romas" (Momigliano, 1991, p.9).

0 que que se está querendo dizer com esta citação é que o Judaísmo, a religião que diretamente deu origem a Cristianismo, é desde o seu início, explicitamente, uma forma de individualismo atuante e pragmático ${ }^{7}$. Atuante pelo fato de que toda a história do povo de Israel repousa num acordo, numa aliança ao mesmo tempo coletiva e pessoal com Deus. Pessoal, porque estabelecida também individualmente com cada um dos membros que compunham a comunidade primitiva dos hebreus. Neste caso, 0 que é enfatizado desde o início pelos judeus é a religião como o centro da sua vida social, expressa na formula o individuo-em-

6. Conforme Arnaldo Momigliano, colaborava um acontecimento até entáo inédito, pelo menos na escala em que ocorreu: o fato de que diferentes civilizaçōes que at entăo năo se conheciam, não tinham sido até entăo confrontadas, passaram a se-lo intensamente neste periodo. Cf.MOMIGLIANO, Arnaldo. Os Limites do Helenismo. Fio de janeiro: Jorge Zahar Editores, 1991.

7. Para uma concisa apreciaçăo do Judaismo, veja-se SIMON \& BENOIT. Judaísmo e Cristianismo Antigo: de Antíoco Epifánio a Constantino. Săo Paulo: Ed.Pioneira/EDUSP, 1987. 
relaçăo-com-Deus, o que conferiu um caráter acentuadamente étnico, comunitário, e ao mesmo tempo particularista, à vida social judaica. Porém, os judeus, ao proclamarem a religião como o centro de sua vida social, nunca deram a ela um significado clvico como os gregos, para os quais a religião dizia respeito à cidade, a cidadania e portanto assumia um caráter essencialmente politico. 0 Judaismo não é uma religião da cidade ou de qualquer outra coisa deste tipo. Ela é a religião coletiva do povo de Israel, baseada numa aliança mistica entre este e o seu Deus revelado, mas que ao mesmo tempo reconhece a dimensão individual e privada existente neste acordo, uma vez que para os judeus existe, em principio, a idéia de que todos os homens devem aderir ao monoteísmo pela sua fé neste Deus. Sendo assim, em nenhum momento, mesmo na época dos reis, os judeus admitiram submeter a sua experiência religiosa a qualquer outra experiência social ou política. Não existia para eles, portanto, a idéia de cidadania. 0 que existia era uma comunidade de língua, de fiéis que aceitaram a idéia de um só Deus e assumiram sua aliança com ele. Esta aliança que foi consignada em um Texto, tornado doravante 0 centro de referência para a sua cultura, era o que realmente comandava todos os domínios da vida entre os judeus. Além disso, este Deus não pertenceu a nenhum panteão cívico anteriormente conhecido. Ele era um Deus do deserto que se revelou pela primeira vez a um grupo de pastores nômades cujos descendentes somente mais tarde fundariam e optariam por viver numa cidade. De qualquer forma, não é a cidade enquanto modo de vida que interessa aos judeus, mas sim a terra sobre a qual ela se encontra, a Terra de Canaã, a sua Terra Prometida. Aliás, como veremos mais adiante, todas as reivindicações feitas por algumas seitas do Judaísmo sobre a "recuperação da sua pureza original" tem como cerne a questão da cidade, vista como modo de existência que conduz à perdição, à idolatria, aos vícios, à impureza e à perda dos autênticos valores ${ }^{8}$.

Bem entendido, Judaísmo e Cristianismo não se separam logo após a morte de Jesus. É preciso ainda algum tempo para que a separação ocorra. De acordo com as versões autorizadas, ela ocorre quando um grupo de judeus da diáspora, helenizados e cristianizados, denominados helenistas pelas autoridades judaicas palestinas, estabelecem-se em Jerusalém. A principal questão que envolve os dois grupos diz respeito à condenação radical que os helenistas faziam ao Templo de Jerusalém. Através de Estevão, seu lider, "parecem ter identificado em Jesus 0 encarregado da missão de espiritualizar o culto pela eliminação do falso santuário e devolver (...) ao Judaísmo sua pureza original" (Simon \& Benoit, 1987, p.96-7). Segundo estes historiadores, o conflito culmina com a morte de Estevão que se torna, assim, o primeiro mártir cristão - e com a dispersão do restante do grupo pelo mundo afora, constituindo a primeira missão cristã.

0 problema é que esta versão nos coloca diante de uma reivindicação tradicional no Judaísmo, para a qual existem pelo menos duas interpretaçōes diferentes. A primeira delas diz respeito à comunidade dos essênios que declaradamente, conforme demonstram os manuscritos encontrados no Mar Morto, sempre se mostraram também contrários ao Templo, fazendo a este um tipo de

8. Veja-se a este respeito os Manuscritos do Mar Morto, nos quais através dos Preceitos - em especial, o Preceito da Comunidade - é nítida a oposição feita ao modo de vida levado na cidade. Cf. VERMES, G. Os Manuscritos do Mar Morto. São Paulo: Ed. Mercuryo, 1991. 
acusação muito semelhante à que fazia Estevão. Ora, esta comunidade e seita que tem a sua origem na época Macabéia, tendo desaparecido somente no meio do turbilhão dos acontecimentos do ano 70 d.C., embora tivesse sofrido diversos tipos de reveses por parte das autoridades judaicas ligadas ao Templo, parece não ter demonstrado em nenhum momento de sua longa existência a intenção ou disposição de desligamento do Judaísmo, da mesma forma que para estas mesmas autoridades judaicas nunca foi vista "fora" dele. Ao contrário, os manuscritos até agora divulgados e estudados demonstram claramente que os essênios consideravam-se judeus, apenas mais judeus do que todos os outros. Eles eram também considerados e aceitos como tais e praticavam uma doutrina de estrita obediência à Lei. A segunda interpretação diz respeito às Sinagogas, pois desde 0 período helenístico vinham colocando esta reivindicação, em função do papel que desempenharam no desenvolvimento do Judaísmo, principalmente entre os judeus da diáspora. Um papel que dentro da mistica judaica se encontra intimimamente associado ao desenvolvimento de uma hermenêutica $e$, portanto, de uma relação com o texto biblico inteiramente distinta daquela implícita no culto praticado no Templo. Além disso, em termos da prática religiosa, a Sinagoga representava uma tendência mais particularista de acentuado cunho congregacional. Pelo que escrevem os historiadores do Judaísmo deste período, tudo indica que no Templo o texto bíblico era tomado mais como uma legislação e um sistema de prescrições rituais strictu sensu a partir dos quais os sacerdotes exerciam de fato o controle social sobre a comunidade. Na Sinagoga, ao contrário, o que parece ter sido enfatizado, principalmente na diáspora, foi uma tradição do estudo voltada para a transmissão do conhecimento do texto bíblico, não apenas do texto em si mas de toda a tradição oral dos comentários rabínicos e de todo o tipo de reflexão interpretação e exegese - que o texto bíblico suscitou ao longo do tempo entre os judeus. Vemos assim que, em razão desta tradição de estudo, não foi por acaso que algumas Sinagogas da diáspora acolheram bem a Filosofia.

Ora, por conta deste fato, sabe-se que sacerdotes e rabinos há muito disputavam entre si o lugar de proeminência na hierarquia religiosa judaica. E 0 cerne desta disputa foi sempre apresentado como a pretendida restauração da pureza do Judalsmo, mas al basicamente através da preservação da pureza do conceito de Deus. 0 que significa isto? Neste momento é necessário que mencionemos 0 historiador Gershon Scholen ${ }^{9}$, pois ele nos fornece uma explicação sobre 0 desenvolvimento da mistica judaica e, por conseguinte nos apresenta as razões para esta reivindicação do ponto de yista rabínico: trata-se da preservação a qualquer custo daquilo que os judeus consideram a suprema função da sua religião, em particular: desfazer todo e qualquer conteúdo mítico que possa existir nas relaçōes entre os homens e Deus. Em outras palavras, trata-se da exclusão da realidade do Deus vivo ${ }^{10}$.

9. CT. SCHOLEN, G. G. A Cabala e seu Simbolismo. São Paulo: Editora Perspectiva, 1978, p.107-8.

10. "A história do Judaismo, numa extensăo maior talvez do que a de qualquer outra religião, 6 a história da tensão entre estes dois fatores - pureza e realidade viva -, uma tensão que tem sido aumentada naturalmente pelo caráter especial do monotelsmo judaico. Porque no Judaísmo tudo dependia de preservar e explanar a unidade pura desse Deus, de salvaguardar a idéia de Deus contra todas as mesclas com elementos pluralistas. Mas preservar ao mesmo tempo a realidade viva de Deus - isto 
Pelo que pudemos constatar acima, cremos que temos argumentos suficientes para podermos dizer que a "recuperação da pureza original do Judaísmo" constitula uma velha questão dentro do quadro religioso judaico. Mas se não é assim, o que provocou a mudança e levou à separação dos cristãos? Ou melhor, que sentido eles deram a esta reivindicação?

Como vimos anteriormente e considerando que a contribuição da civilização helenistica na origem e no desenvolvimento do Cristianismo se fez presente inicialmente através das Sinagogas da diáspora, pois estas já tinham uma tradição de conhecimento e de utilização das categorias de pensamento gregas, temos então, em resumo, dois tipos de renunciador: de um lado, um renunciador e uma forma de ascese que se satisfaz com o "distanciamento inteligente do mundo" (mundo helenístico); de outro, um renunciador cuja forma de ascese, por se encontrar totalmente centrada na fórmula o individuo-em-relação-com-Deus, recusa o mundo tal como ele é.

É a partir do encontro dessas duas "formas de individualismo" que se elabora a diferença entre o Judaísmo e 0 Cristianismo no que se refere à concepção que possuem de mundo ${ }^{11}$ e do estatuto que conferem a ele nas suas respectivas doutrinas. Entender esta diferença geral entre ambas as religiões, no momento em que se separaram, leva-nos de certo modo ao cerne da chamada civilização ocidental no que se refere ao lugar que ela confere ao conflito e à diferença, isto é, a esta incompatibilidade instaurada entre 0 Homem e 0 Mundo como conseqüência do seu afastamento da presença divina. Mas enquanto no Judaísmo a ordem do mundo - não a restauração da sua perfectibilidade primordial - fica assegurada pela preservação da Aliança anterior através da obediência à Lei mosaica, no Cristianismo, tanto a ordem como a integridade original do mundo são recuperadas pela Nova Aliança 12 estabelecida que, diferentemente das anteriores, passa a incluir todos os homens e os coloca igualmente quitados diante de Deus, prontos para viverem com ele de novo em sua glória. De fato, o Judaísmo e o Cristianismo são religiōes essencialmente históricas, mas é preciso termos em mente, porém, que ambas as religiões conferem distintos significados à esta possibilidade de mudança e de regeneração do mundo, uma vez que ambas se colocam de modo diferente com relação à questão do tempo ${ }^{13}$.

requeria um equilibrio perfeito entre os dois fatores, e este equilibrio sempre fol precário". SCHOLEN, G. G. idem, p.107-8.

11. 0 termo mundo vem do latim mundus, tradução da palavra grega kosmos. 0 conceito de mundo implica a idéla de uma totalidade, de uma ordem constitulda no tempo e no espaço. Segundo Gianni Micheli, "mundo significa a totalidade das colsas como objeto estabelecido; diferencia-se portanto de natureza, que significa a totalidade das coisas existentes com particular incidência nos seus principios constitutivos essenciais... 0 nascimento do conceito de mundo acontece numa fase avançada do processo de conhecimento das res, quando estão já constituidos os conceitos abstratos de totalidade e de ordem". Cf. MICHELI, Gianni. Mundo. In. Enciclopédia Einaudi, vol.18. Lisboa: Imprensa Nacional - Casa da Moeda, 1990, p.171-194.

12. Segundo o conceito neotestamentário de Deus, ele é fundamentalmente Amor. Por conta disso, para os cristãos, houve uma Nova Aliança: de tal maneira Deus ama o Mundo que enviou seu Filho para salvá10.

13. Segundo Walter I. Rehfeld, o Judaismo convive com dois conceitos de tempo: 0 conceito de eternidade (a sincronia) e o conceito de História (diacronia). Ct. REHFELD, Walter I. Tempo e Religiåo. São Paulo: Ed. Perspectiva, 1988. 
Embora o messianismo tenha se desenvolvido nos quadros do Judaísmo tradicional, é preciso dizer que nada nos autoriza a afirmar que ele tenha recebido sempre uma interpretação mística da parte dos judeus ${ }^{14}$. 0 messianismo no contexto judaico, na maiorida das vezes em que ele irrompeu, assumiu um caráter étnico e nacionalista, ou seja, de reação contra uma situação de dominação estrangeira explícita que colocasse em xeque o modo de vida do povo e a existência do Judaísmo, como é o caso dos acontecimentos que culminaram com a Revolta Macabéia. Portanto, nada há que comprove que todos os judeus vivessem a promessa messiânica, nos termos em que ela foi experimentada entre os essênios e os cristãos, isto é, como um elemento essencial da sua doutrina. Assim, para o Judalsmo, em tempos normais, esta promessa de regeneração do mundo podia ser obtida pela via da obediência à Lei. Em última instância, era esta obediência que, ao determinar e conformar uma regra de vida, preservava a aliança entre Israel e Jeová. Além disso, esta aliança era estendida a todos os judeus, ao mesmo tempo em que a sua preservação dependia também de todos, fato este que conferia um sentido igualitário e comunitário à vida social e religiosa judaica. Há um aspecto também a ser ressaltado quanto ao sentido étnico e nacionalista que 0 Judaísmo conferia ao messianismo: é o fato de que a aliança entre Jeová e Israel, feita no Sinai, estar intimamente associada a uma Terra prometida, entendida como uma terra sagrada. Assim, povo (Israel) e Terra (Canaã) são dois elementos básicos do messianismo judaico, não existindo um sem o outro. No entanto, houve momentos em que, vivendo situações críticas, foi necessário que esta promessa recebesse o reforço de uma confirmação personalizada na figura dos profetas. Discutir o papel do profetismo judaico na gênese e no desenvolvimento do Cristianismo e do messianismo cristão é crucial, uma vez que toda a justificação da vinda, da divindade e da paixão de Cristo supõe a afirmação da credibilidade nestas profecias. Mas é preciso reafirmar que, diferentemente do Judaísmo, o cristianismo opta a partir de um dado momento por uma perspectiva universalista. É neste contexto que podemos retomar as reinvidicaçōes atribuidas aos primeiros cristãos e que culminaram com a separação das duas religiōes.

É conhecido 0 desapontamento dos seguidores contemporâneos de Jesus com relação à sua morte, 0 que deu origem à crença nas duas vindas do Messias, isto é, as duas parousias. a primeira vinda em que ele é sofredor e passivo (o Cordeiro de Deus); a segunda, em que ele desce do céu como vencedor, apresentado como Rei no sentido helenistico do termo, isto é, como Salvador (Sóter) para julgar todos os homens. Mais exatamente, foi a crença numa segunda vinda do Messias que sustentou as primeiras comunidades cristãs durante 0 primeiro século, dando a elas condiçōes ao mesmo tempo de sobreviverem no contexto pagão e de construirem sua identidade diante do conjunto das outras seitas judaicas - como os essênios e os zelotes - com os quais os cristãos possuiam

14. Os essênios representam a grande excessão no contexto do Judalsmo. Mas mesmo assim, tudo indica que na época de Jesus, ja havia vindo, para eles, um Messias na figura de um personagem bastante citado nos manuscritos: 0 Mestre da Justiça. Desse modo, o Messias deles não foi e nem poderia ter sido Jesus. É muito possivel que Jesus tenha frequientado a comunidade, conhecesse-a e tivesse ligaçōes com seus membros. De qualquer modo, os essênios praticavam uma doutrina messiannica e apocaliptica que muito deve ter influenciado os primeiros cristãos, expressa na convicção de que eram 0 verdadeiro Israel", isto é, "o que restou do verdadeiro Israel". 
algumas semelhanças. Mas nos séculos seguintes ficou evidente que a crença numa segunda vinda do Messias para instaurar definitivamente, aqui e agora, o Reino de Deus não era suficiente para superar todos os desafios enfrentados pelo Cristianismo, principalmente a partir do momento em que Paulo proclamou a vocação universalista dele. Em virtude disso, tendo que competir com as diferentes religiōes que também ofereciam uma relação mais pessoal com a divindade e também com as diferentes escolas filosóficas helenisticas, o Cristianismo foi levado a traduzir a sua experiencia para os quadros do pensamento grego. Mais do que isso, teve que demonstrar para um páblido ilustrado (helenizado) que a sua doutrina possula uma racionalidade e que esta repousava sobre pressupostos muitos semelhantes aos da Filosofia. De fato, este processo de tradução foi tão evidente que podemos dizer que a partir deste momento - séculos II e III - começou a se verificar uma tensão no interior do próprio Cristianismo e que 0 acompanharia desde então: trata-se da oposição entre a fé e a razão. Se de um lado, diante de um "público interno", isto é, de judeus, igualmente monoteístas, Jesus é o Messias, essencialmente o Cordeiro de Deus anunciado pelos profetas; de outro lado, diante de um "público externo", composto de pagãos ilustrados e filósofos, ele é o "Logos ... que tomara a forma humana em Cristo" e que já tinha sido pré-anunciado pelos gregos (Sócrates) e Platão (Jaeger, 1991, p.45).

Até onde podemos nos manifestar sobre a utilização da Filosofia pelos cristãos durante os séculos II e III d.C., temos que concordar que tal fato foi imprescindivel para o Cristianismo poder sustentar o seu projeto universalista diante do contexto pagão. Segundo Werner Jaeger, neste sentido, a construção de uma teologia cristã só foi possível a partir dos elementos e das categorias de pensamento gregas. Mais do que isso, foi um imperativo sem o qual ele dificilmente ultrapassaria as resistências encontradas. Além disso, seria também a construção de uma teologia que garantiria, em última instância, ao Cristianismo a possibilidade de poder reivindicar para si a legitimidade de sua autonomia já alcançada de fato, em relação ao Judaísmo.

A conseqüência disso foi que a partir do século III d.C. esta teologia e, por causa dela, o Cristianismo póde oferecer ao Império Romano algo de que este tanto precisava e que o paganismo e a Filosofia não podiam mais lhe dar: trata-se dos fundamentos com os quais o Império Romano póde forjar um novo conceito de cidadania. Um conceito que possibilitava o estabelecimento de um novo nexo entre este Indivíduo - o individuo-em-relação-com Deus - cada vez mais emergente, com uma forma de desempenho da cidadania que satisfizesse as novas exigências da vida pública no Império, sem se incompatibilizar com algo que já se tornara um valor em si mesmo desde o estoicismo, o epicurismo e o ceticismo: a vida privada combinada com uma nova forma de subjetividade. Ora, o Cristianismo, pela herança recebida do Judaísmo, também valorizava esta forma de vida baseada numa relação pessoal e privada com Deus ${ }^{15}$. A diferença estava no fato de que ao contrário do

15. 0 texto bíblico ao mencionar as inúmeras ocasiões em que Jeová revelou-se aos judeus, assinala que na maioria das vezes ele o fazia elegendo um personagem como porta-voz de sua mensagem. A Biblia mostra ainda que esta escolha recala em um momento preciso: na maioria das vezes, os escolhidos estavam no recesso da sua intimidade, isto é, dormindo e sonhando, ou então, em situaçóes nas quais encontravam-se "fora" do convivio com outros homens. Ora, o sonho que é um dado importante para se entender muitas das particularidades religosas e misticas do Judaismo, bem como a condição de 
Judaísmo tradicional, no Cristianismo, Deus não guardava mais um significado étnico e particularista. Tinha se transformado no Deus universal do Amor, que abarcava $e$ inclula toda a humanidade em sua promessa de salvação, num igualitarismo mais radical ainda do que aquele professado pelo Judaísmo. Ao contrário, dos sistemas filosóficos acima, o Cristianismo năo se satisfazia com um "distanciamento inteligente" do mundo. Era preciso transformar o mundo, portanto, agir sobre ele, prepará-10 para receber a mensagem divina. Foi assim, com a sua doutrina baseada em uma Nova Aliança e no amor ao próximo, que o Cristianismo pôde dar um novo significado à noçăo romana de concordia ${ }^{16}$, satisfazendo melhor do que qualquer outra religiấo ou sistema filosófico anterior as novas exigências geopoliticas, culturais (simbólicas) de uma nova civilização emergente.

Mas se tudo isso é verdade, isto é, se do ponto de vista intelectual a Filosofia foi crucial para a garantir a elaboração de uma Teologia Cristã, o sucesso do Cristianismo, principalmente entre um público não letrado, não pode ser imputado exclusivamente a esta relação, visto que além da Filosofia ele competia com várias outras práticas religiosas. Nesse sentido, que outra qualidade ele poderia apresentar para poder disputar com estas outras religiōes, muitas delas religiões de mistério e poder "convencer" um imenso público não apenas intensamente exposto a elas como seduzido pelas idéias de "salvação" que elas veiculavam?

Ora, é neste momento que temos que nos deter nas preocupações lançadas por alguns teólogos cristãos como Tertuliano e Taciano ${ }^{17}$, pois elas são esclarecedoras do tipo de ameaça que, segundo eles, começava a pairar no ar: ou 0 Cristianismo preservava o seu caráter supra-racional, reafirmando a superioridade da fé no Cristo salvador, messiânico, enfim, preservava a sua "pureza de culto bárbaro", conforme escreveu Taciano - o que evidentemente o tornava mais atraente do ponto de vista das massas - ou, ele se diluiria transformando-se em mais um sistema filosófico, à medida que substituísse o carater divino e místico de sua mensagem por uma visão apenas ética e paidêutica, ficando assim novamente restrito a uma elite. Neste caso, a indagação feita por Tertuliano sobre "o que tem Atenas a ver com Jerusalem ou a Academia com a Igreja?" (Jaeger, 1991, p.51), para nós, longe de apontar somente para uma intolerância em relação ao sincretismo existente, ou de ser apenas a prefiguração da forma latina do Cristianismo, denuncia uma percepção do papel estratégico quanto a este caráter de "culto bárbaro" para a sua disseminaçăo e consequente vitoria sobre as demais religiōes. Ora, entender isso é crucial para a compreensão do Cristianismo enquanto

"afastamento" do convivio humano exigidas, são provas de que, entre os judeus, esta experiencia pessoal com Deus 6 fundamental e intransferivel.

16. Concordia é a expressăo romana para a palavra grega homónoia. Segundo Werner Jaeger, no período romano ela tornou-se uma deusa. Sua imagem estava presente em moedas romanas e ela era invocada em cerimónias públicas e privadas (núpclas) por cidades inteiras. Os filosofos a louvaram "como o poder divino que subjuga o universo e sustenta a ordem do mundo". 0 Cristianismo com a sua mensagem centrada no Deus Amor e Salvador do Mundo proporcionou um novo significado para ela. Ct. JAEGER, Werner. Cristianismo Primitivo \& Paideia Grega. Lisboa: Ediçōes 70, 1991, p.28-9.

17. 0 objetivo do trabalho de Werner Jaeger 6 o de demonstrar a capacidade religiosa da Filosofia grega e, como neste caso, isto foi crucial para o desenvolvimento da Teologia Crista. No entanto, o autor registra a resistencia que este processo de traduçäo encontrou logo nos primeiros séculos e o sentido para o qual esta resistencia apontava. Cf. JAEGER, Werner. idem, op. cit. 
sistema religioso e de pensamento, a saber: que o caráter messiânico de sua doutrina nåo é apenas um fato circunstancial de sua história, um elemento de seu processo formativo a ser superado posteriormente. Ao contrário, ele é um dado constitutivo, um elemento estrutural, portanto um paradigma simbolico e de ação cujo coroamento 6 a própria imagem do martírio de Cristo ${ }^{18}$ - sem a qual ele deixa de existir e perde por completo a sua identidade religiosa, podendo ser assimilado a qualquer sistema ético e/ou filosófico existente.

Esta preocupação, que já aparece nos séculos II, III e culmina na crise do século IV d.C., so nos demonstra 0 quanto 0 esquecimento deste elemento inaugural, mas essencial e estratégico, pode nos fornecer uma visão distorcida dos desdobramentos do Cristianismo a partir de então. Assim sendo, conforme podemos perceber através das fontes, este processo de tradução do Cristianismo para a Filosofia encontrou resistência. Contudo, elas nos mostram que esta resistência, como as apresentadas por Tertuliano e Taciano, referem-se a uma constatação que já podia ser feita naquele momento: ao mesmo tempo em que o Cristianismo se difundia rapidamente entre um público ilustrado, ele também passava a correr o risco de perder a sua identidade e unidade como religião.

Para concluirmos, podemos dizer que a retomada do contexto inaugural do Cristianismo permite ao antropologo interessado no estudo do Messianismo contemporâneo chamar a atenção para o fato de que a "exclusão" tanto em termos teológicos, históricos, políticos quanto sociologicos dos diferentes movimentos sociais que buscam refúgio no paradigma messiânico para darem sentido e legitimidade às suas demandas, pode revelar o completo desconhecimento de que estes movimentos longe de expressarem uma forma de "irracionalidade" ou falta de compreensão para com as fontes originais do Cristianismo, estão na verdade atualizando estas mesmas fontes. Mais do que isso, ao fazê-lo, estāo reproduzindo as condições a partir das quais esta tensão original e interna do próprio Cristianismo, possa continuar a cumprir o seu papel estratégico, isto é, o de manter reunido no interior de um mesmo sistema religioso as dimensōes propriamente racional e supra-racional. Condições sem as quais ele já teria desaparecido enquanto religião diluido exclusivamente numa ética ou num sistema filosófico. Nesse sentido, para nós, o estudo desses movimentos no mundo moderno, é importante porque nos obriga a lembrar que 0 Cristianismo com a sua perspectiva messiânica foi a retomada - no quadro do monoteísmo - da idéia de Deus como uma realidade viva e que é este fato que o fez em dado momento ser bem sucedido com relação à sua pretensão de tornar-se uma religião universal.

18. Para usar um concelto de Victor Turner, a trajetória de Jesus culminando com a sua peregrinação; crucificação e consequente promessa de um retorno, constitui o paradigma o o simbolo focal do Cristianismo, a partir do qual se desenvolve toda a simbólica cristă, năo apenas no plano das liturgias existentes, mas também no plano doutrinário. Cf. TURNER, Victor. Image and Pilgrimage in Christian Culture. Anthropological Perspectives. New York: Columbia Un.Press, 1978. 
Asstract: This paper aims to present some discussions about the origins of Christianism. It also intends to put some questions about the current sociological interpretatios of Messianism and its occurrences in the modern and contemporany societies, interpretation that stand that are usual forms of irracionalism or archaism. We'll demonstrate that these approuchs ignore the fact that Christianism from its beginning is related to a tension - the opposition Faith $\times$ Reason - depending on the place and the role of the Hellenistic Civilization and Judaism in the moment of its birth.

Ker-words: Primitive Christianism, Judaism, Messianism, Syncretism, Hellenistic Civilization.

BibLIOGRAFIA

DUMONT, Louis. Essais sur L'Individualisme: une perspective anthropologique sur l'idéologie moderne. Paris: Éditions du Seuil, 1983;

DURKHEIM, Émile. Les Formes Élémentaires de la Vie Religieuse. Paris: Presses Universitaires de France, 1960;

JAEGER, Werner. Cristianismo Primitivo e Paideia Grega. Tradução de Artur Mourão. Lisboa: Edições 70, 1991.

MICHELI, Gianni. Mundo. In. Enciclopédia Einaudi, vol.18. Tradução de Rui Santana Brito. Lisboa: Imprensa Nacional/Casa da Moeda, 1990, p.171-194.

MOMigliano, Arnaldo. Os Limites da Helenização: a interação cultural das civilizações grega, romana, céltica, judaica e persa. Tradução de Claudia Martinelli Gama. Rio de Janeiro: Jorge Zahar Editores, 1991.

REHFELD, Walter I. Tempo e Religião. São Paulo: Ed. Perspectiva, 1988.

SCHOLEN, Gershon. A Cabala e seu Simbolismo. Tradução de Hans Borger e J. Guinsburg. São Paulo: Ed. Perspectiva, 1972.

SIMON \& BENOIT. Judalsmo e Cristianismo Antigo: de Antloco Epifânio a Constantino. Tradução de Sônia Maria Siqueira Lacerda. São Paulo: Ed.Pioneira/EDUSP, 1987.

TURNER, Victor. Image and Pilgrimage in Christian Culture: Anthropological Perspectives. New York: Columbia Un.Press, 1978.

VERMES, Geza. Os Manuscritos do Mar Morto. Tradução de Júlia Bárány Bartolomei e Maria Helena de Oliveira Tricca. São Paulo: Ed. Mercuryo, 1991.

WEBER, Max. A Ética Prostestante e o Espirito do Capitalismo. Tradução de M. Irene e Tamás Szmrecsányi. São Paulo: Editora Pioneira, 1967. 